\title{
LEGAL, ETHICAL AND SOCIO-ECONOMIC ASPECTS OF COMMUNITY TELECARE
}

\author{
R. Sethi", G. Bagga ${ }^{\dagger}$, D. Carpenter ${ }^{* *}$, D. Azzi ${ }^{*}$, R. Khusainov ${ }^{*}$ \\ *Dept. of Electronic and Computer Eng., ${ }^{* *}$ School of Social, Historical and Literary Studies, University of Portsmouth, UK \\ ${ }^{\dagger}$ Faculty of Medicine, University of Sheffield, UK. Correspondence email: richie.sethi@ port.ac.uk
}

Keywords: telecare, elderly, legal, ethical, socio-economic

\begin{abstract}
Legal, ethical and socio-economic factors in community telecare differ from those pertaining to telemedicine and are examined with reference to older persons' care. Issues discussed include equipment liability, service malpractice, technical and service standards, consent (including the Mental Capacity Act), research, trials, human factors, dependence, privacy, security, accessibility, quality, affordability, social inequalities and community factors.
\end{abstract}

\section{Introduction}

Telemedicine (clinical care by means of live teleconsultation or monitoring of clinically-relevant health parameters) can be distinguished from community telecare (social care, including emergency alarms, dementia care, assisted living, and longer term wellbeing management). The commonality between the two is in equipment, telecommunications and a health service, thus they share some legislative and ethical areas such equipment, malpractice and consent.

The growing demand for telecare gives rise to a heightened need for stakeholders to be mindful of legal, ethical implications and socio-economic factors. The differences in technology and application lead to different issues and the ethical and social issues are also significantly greater due to the nature of patients and non-regulation of the service.

This paper carries out a thorough analysis of the applicable legal, ethical and socio-economic aspects of community telecare for older users and focuses on issues which most differ in relation to telecare, and makes recommendations. It is based on a systematic analysis of legislation, regulations, civil and administrative decisions and relevant literature. Where appropriate, reference to case law will be made. The legal aspect discuses equipment liability, service malpractice and technical and service standards; the ethical aspect, consent, research, trials and human factors and dependence, privacy and security; and the socio-economic aspect, access, quality, affordability, inequalities and community factors.

\section{Legal Aspects}

Community telecare is largely self-regulated [1] and lacks the level of clarity in regulation and legislation as its clinical service counterpart for which existing medical laws may apply. Although litigation will clarify the de jure status, as with telemedicine, most legal aspects may be examined by extrapolating existing telecommunications, information services, product and service and social care laws [2]. However, as telecare is a unique combination of communications, computing, medical devices and social care, telecare users are ergo de facto patients as well as care recipients and consumers; consequently the service can involve several ethical issues, which complicates which regulations apply and indeed how to apply those that do.

The legal issues involved are centred around three main areas: equipment liability, service malpractice, and technical and service standards.

\subsection{Equipment Liability}

Telecare devices must comply with the EU Directive concerning medical devices (93/42/EEC), and additional ancillary Directives, the core principal of which is compliance with essential requirements; to obtain a ' $\mathrm{CE}$ mark' before being marketed [3]. The Medicines and Healthcare products Regulatory Agency (MHRA) regulates the specification, sale and use of health care equipment in the UK using a classification system, where a higher classification reflects greater risk. Telecare products, being non-invasive, are normally in Class 1 (low risk), whereas telemedical equipment which involves active diagnostic devices are in Class 2 or 3 . Class 1 devices may be self-certified by the manufacturer to indicate compliance with relevant standards and Directives. Future telecare systems which monitor physiological processes would potentially attract a higher classification and therefore stricter regulation, which involves an audit and conformity assessment by a Notified Body.

The MHRA also issues advisories on defective equipment and can ban its sale. Product liability describes the civil liability of manufacturers and others, for any harm caused by product defects [3]. The liability for telecare equipment in practice is usually contractual and lies with the body supplying the equipment, which in most cases are local authorities. Although it may be argued that de jure, in a health service, where a user is supplied with a product not purchased directly by them, the user will not be in a contractual relationship with the provider [3], telecare provided by local authorities is subject to means-testing and paid for, eventually, by personal budgets or a combination or public and private finance and involve a needs assessment and commissioning, which implies a contractual relationship and thus liability. 
Meanwhile, warranties for telecare services are implied and this extends to information systems, even when a contract seeks to limit liability, with these provisions having been used successfully by customers of faulty computer software [3].

The secondary civil route is the tort of negligence, where no direct contractual relationship is required [3] and the third route is provided for by the EU Directive on defective products (85/374/EEC) for damage caused by a defect, where negligence does not need to be proven by the claimant [3]. In both cases, liability extends to all parties identified in the service chain (although Courts have the prerogative of assessing the length of the chain); which includes the reseller, those responsible for installation and maintenance, the alarm monitoring centre, telecommunication provider and local authority where relevant Criminal sanctions are provided for by the EU Directive on product safety (92/59/EEC) [3].

The legal liability of a telecommunications carrier in event of loss of service as a result of network problems is a grey area [4]. The UK telecommunications regulator, Ofcom, offers voluntary guidelines for ISPs to provide reliable access to emergency services but there is at present no provision for telecare services. Telecare service providers should therefore consider contractual arrangements to specify liability.

\subsection{Service Malpractice}

Older persons, especially those at high risk of injury (e.g from falls) or acute medical conditions associated with age such as cardiac arrest or pneumonia, often become dependent on telecare as a life-critical service, which raises the importance of malpractice in telecare in contrast to home clinical telemedicine, which involves less life-critical risk.

In a negligence claim, the plaintiff must establish that the defendant owed them a duty of care, that the duty was breached and that harm was suffered by that breach of duty. Firstly, the duty of care of a professional telecare service provider is either contractual or implied, as discussed under liability. The duty of care of a non-professional but paid carer may be similarly defined, but that of informal or unpaid carers is contentious. Whilst acting informally, a person does not owe another a duty of care, carers may be regarded as having 'voluntarily assumed responsibilities'. It may however be argued that although morally they owe a duty of care to their charges, their obligations are not defined; Herring [5] reports that 'law should be very reluctant to impose criminal duties on unpaid carers.'

Secondly, breaches in the duty of care depend on the appropriate standard of care. Bolam v. Friern Hospital Management Committee 1 WLR 582 at p.586 sets the precedent of the Bolam test, which states that a doctor is not liable in negligence if he has acted in accordance with the relevant standard of care as set by 'a responsible body... skilled in that particular art.' The Bolam test was later qualified by Bolitho v City \& Hackney HA 1998 AC 232, which stated that the body of professional opinion would still be subject to logical scrutiny. Take the case of an injury suffered during hours when the telecare system was switched off, and where this practice was in line with professional regulations. The standard of telecare, despite being in accord with a professional body of opinion, must nevertheless withstand logical scrutiny. In such a case, it may be said that the standard of care is below what is acceptable.

Gold v Haringey HA 1987 clarified that the Bolam test is not limited to doctors, but can also be applied to any health profession involving skill, knowledge or experience, extending the test to the professional/paid carers, although the situation with unpaid/informal carers remains unknown. Social care services or local health authorities may however still be vicariously liable so it falls to the Government to set a minimum standard and for court cases to test that standard's resilience.

Thirdly, suffering of harm (including death) must be proved by 'causation' [2], that is, evidence to show that it is more likely than not, that the telecare service's negligence caused the suffering claimed. The 'but for' test usually applied in medical situations, paraphrased as 'but for the negligence of the service, would harm to the patient have occurred in any event?' [2], may also apply to telecare in situations where, had it not been for the failure of the telecare service, the patient would have still suffered harm. For example, an older person living alone and without a social network, experiences a fall and contacts the telecare provider seeking urgent attention, but a delayed response leads to Tetraplegial Paralysis. The claim will fail, if it is shown that, had he been timely admitted to hospital and treated, it would have already been too late to treat the injury.

Another issue arises out of poor training both of telecare users as well as operators. Service providers must ensure that both groups are assessed at appropriate intervals for proficiency and failing to remedy a situation where either group is insufficiently skilled, to operate the system or to carry out their duties, may be prima facie evidence of negligence [2].

\subsection{Technical and Service Standards}

Whilst conformance to technical standards may provide evidence that a manufacturer has exercised all due diligence to make a product safe, liability of a defective product does not extend to faults in said technical standards. This is of particular importance to telecare, where there are no uniform standards at present, and older analogue alarm standards are increasingly becoming obsolete, resulting in limited technical guidance and thus increased liability for product developers. New telecare standards must seek to resolve this.

Whilst telemedical consultants' professional duty is governed by General Medical Council regulations [2], the duty of telecare personnel is only governed by the Quality Care Commission when professional services become involved in intervention decisions, which may not be the case in community telecare. Indeed a wide majority of older persons living in this setting rely on informal or unpaid carers [6]. Protocols which regulate how telecare services should operate are not compulsory in the UK, despite existence of a voluntary code of practice and accreditation scheme [1]. 


\section{Ethical Aspects}

Telecare is embroiled with ethical issues, especially concerning older vulnerable users and are centred around issues including: consent, liberty, dependence, privacy and security and research and human factors.

\subsection{Consent}

Consent is the legal counterpart of the ethical concept of autonomy. In law, for consent to be valid, it must be given freely, by a competent person, on the basis of sufficient information. Information about telecare should include the benefits and risks associated with its use and should be sufficient to allow the person to weigh various options and choose accordingly, thus respecting their autonomy. If not implemented with caution, services could 'compromise privacy, cause physical risk and increase social isolation' and hence should not be imposed on people, solely on the concerns of others. It follows that effort must be taken to gain consent before the installation process, especially from those with a cognitive impairment [7]. The ability to weigh options, however, will be dependent on the person's competence or mental capacity. For those who lack capacity, the question arises as to how to provide telecare.

The Mental Capacity Act 2005 provides a legislative framework for managing consent for those with reduced mental capacity and is based on the principle that capacity is assumed in the absence of evidence to the contrary and that practicable steps should be taken to help make a decision. The Mental Capacity Act Code of Practice 2007 offers guidance to those working with or caring for adults, who either lack capacity or have reduced capacity, to make decisions, the latter previously being a grey area. The Act clarifies that a decision made on behalf of a person who lacks capacity should be in their best interests. As potential users are likely to be unfamiliar with telecare, information needs to be conveyed in 'creative ways to maximise comprehension and retention' and in a clear and simple manner [7]. Structured tests for information retention and decision-making should be used to establish capacity, or lack thereof. Additionally, the ASTRID project proposes an ethical framework for introducing telecare to people with dementia [8].

A patient's consent to treatment may not be valid if given under duress. Conversely Mr Leslie Burke v GMC [2005] EWCA Civ 1003 held that requests for treatment may be dishonoured if it goes against professional advice. This has an important implication in that it safeguards vulnerable persons from being pressured to accept telecare as a replacement for direct care where this may have negative consequences.

\subsection{Liberty}

Would clients choose to be monitored by telecare, given the intrusion on privacy and liberties? Respect for individual liberty, in contemporary society, tends to take precedence over other ethical considerations including our own welfare. Partly attributable Mill [9], who argued that an individual's liberty should not be interfered with, even for his own good, any well intended interference is seen as paternalistic, giving rise to descriptions such as 'nanny state'.

The provision of telecare will invade privacy and undoubtedly compromise the liberty of the individual. At the same time it has the potential to allow a person at risk to remain in a relatively unsupervised environment. Thus liberties are traded; privacy is trumped by a maximisation of independence. The ethical imperative of respecting autonomy might not be met in full; telecare might be only reluctantly accepted rather than freely chosen and a loss of privacy might be resented but both might be traded, in the pursuit of maximum overall autonomy. Respect for autonomy is not an 'all or nothing' matter; most social care interventions impact upon autonomy, the key issue is the degree to which they enhance or, indeed, impede it. The refusal of telecare treatment, against professional advice, should not imply cum inpax and advanced directives in respect of refusal of such treatment are legally binding [7]. Such a decision might appear irrational, but in a situation of balancing liberties, priorities might vary; a person might not wish to trade their privacy for greater safety and security.

\subsection{Dependence, Risk and Privacy}

Telecare should be viewed as one element of a comprehensive care plan; over-reliance should be avoided. Telecare is not without risk, which can include service reliability, such as the handling of emergency calls and alerts. Potential users should be informed of all limitations and risks. Chester v Afshar [2004] UKHL 41 Pt 2 held that a patient has a right to be informed of a small, but adverse, risk of injury. There are potential risks with the involvement of informal or unpaid carers but Perry et al. [7] suggest that rigorous vetting procedures may be disproportionately bureaucratic for them. Also, whilst telecare is designed to reduce risk, judging in 'best interest', may overestimate risk, resulting in overprotection, which can restrict independence; there should be a careful balance between protection and independence [7].

Telecare may affect privacy, a basic human right, by on one hand reducing the need for privacy to be compromised by attending carers and, by the degree of information collected by the service on the other [7]. Such information can include people's movements, personal sanitation and condition of health. Telecare users and carers should be informed, prior to installation, about what information will be collected and how it will be used [7] and this should only be that which can promote independence, safety and wellbeing and should be securely stored. The privacy and risk implications of the proposed telecare service should be conveyed, ideally by someone without a vested interest in delivering it [7].

\subsection{Research and Human Factors}

Research in telecare involving participants, either for surveys or product trials should always be subject to ethics clearance procedures of either Local or Regional Councils or the NHS, depending upon the participant group. MHRA guidelines 
regulate clinical trials for non-CE marked medical devices in the UK. A 60-day assessment period involves a comprehensive evaluation of ethical as well as health factors.

Older people and those with reduced cognitive function often find it difficult to operate newer technology. Human Factors (HF) should be used in the design of the user interface, operation and setup of telecare equipment and service to ensure ease of use. The ETSI publishes HF recommendations for telecare (ETSI TR 102 415:2008).

\section{Socio-Economic Aspects}

Daniels [10] claims that healthcare is 'special' because it keeps humans functioning at a higher level than they would without it and reasons that effective healthcare satisfies a unique need. This principle of health preservation could be extended to domiciliary social care; Daniel argues that preserving health requires the expenditure of resources on people in their homes as well as in medical facilities when this health is lost. The socio-economic problems around telecare can be centred around five main areas: access, quality, affordability, inequalities and community factors.

\subsection{Access}

The advent of telecare was possible thanks to the medical profession using new technology as it became available [11]. A very real problem with providing telecare in the modern age, however, is that the infrastructure for its use may be unavailable to potential customers. One practical consideration is that not everyone has access to a telephone which they can readily use and the quality of these lines is uncertain. If the patient and the telecare team cannot communicate, there is little value in subscribing to telecare services. There are two further potential problems here. One is that patients who need telecare but live in areas where it is unavailable may have to choose between relocation (often resulting in social exclusion) and continuing without adequate monitoring. It may be said then, that telecare may not improve the delivery of social care to these secluded parties.

The UK lags behind some EU countries and the likes of USA, Korea and Japan in high-speed internet penetration and availability [12], in spite of having prices lower than the EU average [13]. This has hindered the progress of nextgeneration telecare which involves 'the prediction of possible acute situations' [14] from sensory data and which involves large amounts of data. Currently, only $4 \%$ of over-65s have access to the internet in any form in their homes and are the group most resistant to internet access [15]. This means that providers may have to add extra costs (including internet fees) for anything other than the most basic telecare.

Further, the uptake of IP-based telecare services in the UK will be contingent upon guarantees of reliability of the telecommunications link. Private circuits offer better reliability than broadband Internet, but are cost-prohibitive and it follows that ISPs which implement Quality of Service techniques to reserve bandwidth for telecare services will stand to gain as the industry moves away from analogue telephony towards bandwidth-intensive digital services.

\subsection{Quality}

Not all telecare services are homogenous in provision and hence quality. There is no evidence to suggest that differences between the public and private sectors in the quality of social care services and sheltered accommodation extends to telecare services, although it is recognised that there is at present a lack of qualitative analysis of private versus public provision of telecare. Regardless of any difference in the quality of service however, there exists a false dichotomy between the public and private sectors; both share a core motivation when offering telecare - the wish for 'reasonable financial reward' while meeting the desires of clients [16].

Additionally, the success of telecare within one area depends on how well the organisation providing it communicates with other social care and medical organisations [17]. Despite the ideological differences between the groups (which may not even exist, as stated above), a partnership between publicly and privately-funded enterprises may be the only available solution. In 2001, 60\% of telecare provision by local authorities involved some degree of co-operation between government and private enterprises [18]. Perhaps, then, this distinction is less relevant than it first seems.

There is also a marked difference in the quality of telecare between rural and urban areas [19]. If telecare can be a preventative, and therefore a cost saving measure, then there is an argument that those rural areas where admission may cost more (due to transport costs and increased morbidity), should have telecare services improved. At present, the lack of infrastructure predisposes those in rural areas to receiving poorer service than their city-dwelling counterparts. The future may hold a starker contrast, between rural areas receiving only very basic telecare (if any at all) and more urban areas receiving second or third generation telecare, with the outcome of more personalised care for city-dwellers and a one-size-fits-all approach adopted for those in the country.

\subsection{Affordability}

The funding for care in England is means-tested, with those with an income expected to contribute, those with capital between $£ 14,250$ and $£ 23,250$ required to make a contribution from their capital as well as income and those with capital above $£ 23,250$, required to pay the full cost of care [20]. Community telecare services are similarly funded by local authorities. Domiciliary care in Wigan, UK, costs up to $£ 13.28$ per hour and assistive technology $£ 4.72$ per week [21]. For an average pensioner who receives $£ 13,728$ per annum [22], 10 hours of care per week will exhaust $50 \%$ of their annual income and an extra $2 \%$ for telecare seems affordable. The cost however may be less acceptable to some state pensioners, who are guaranteed only £6,760 per annum [23].

In some areas of the UK however, it is available free of charge to those who qualify and increasingly, older person charities are offering free telecare services to those who 
cannot afford it but have a need. Telecare, then, seems affordable for most, albeit putting a strain on income.

\subsection{Inequalities}

Telecare is often cited as an extension of social care services. The Department of Health states that 'Telecare is as much about the philosophy of dignity and independence as it is about equipment and services' [24]. It follows that telecare is also influenced by inequalities within social care provision and associated challenges. Poorer groups have a lower life expectancy and are more vulnerable to multiple health difficulties [25], possibly requiring more intensive care in old age than telecare can support.

The principal benefit of telecare to health authorities is in reducing hospital admissions, which in turn reduces the risk of secondary infections and costs. It can also help to delay the point at which older persons need to move out of their own homes, for more intensive nursing than telecare can support, which has the added benefits of better social inclusion, independence, dignity and greater life expectancy as mortality of those moving out of their homes is greater [6].

Older persons unable to do various tasks and living privately with others are significantly less dependent on social services or paid help- 33\% less for bathing/showering, 17\% for domestic tasks and $23 \%$ for practical activities [6], figures which can be further enhanced by the use of telecare Although some exclusions apply in care means-testing, $41 \%$ of care home residents are self-funded [26] and the costs compel many, especially those from lower socio-economic groups, to sell their assets to pay for care and move into sheltered accommodation. Hence, the service may not be accessible to significant numbers who could have benefited from community telecare had they been able to afford to stay in their own homes. It may be said therefore that state subsidy in telecare alone may not provide the cost savings expected and that reliance on private funding for care is but an ostensible saving. However it is recognised that funding presents a major political issue [6]. Also whilst the Personal Care at Home Act 2010 may improve community care options, there is a need to improve access and affordability of telecare, especially to lower socio-economic groups.

Local telecare strategies override the Department of Health guidance which states that telecare equipment should be provided free of charge, when provided to assist ongoing care, resulting in inconsistencies in telecare charging policies between local councils. For example, some will charge for service and not the equipment, whilst others will charge for both [7]. Another inconsistency is present in the quality of information about telecare options for end users [7].

There is also concern with inconsistent investment in telecare infrastructure. Some local pilot schemes achieve better success than regional ones which suggests that although centralised investment programmes may benefit from economies of scale, a one-size-fits-all approach may not deliver on outcomes due to local variations. Personal budgets however, which epitomise local spending, leads to an increase in costs, and local authorities may not account for telecare in resource planning for these reasons, making it harder to fund and therefore support telecare initiatives.

Furthermore, local authorities often prioritise particular groups such as new clients or those with certain disabilities [7], which makes telecare access more unequal. New outcome-based targets are not immune to these inequalityeffects, as prioritising telecare to those who could have proportionally higher outcome results (which reflects greater cost saving on care packages), could mean that those who do not offer a significant cost-saving may not receive the service.

\subsection{Community}

People are social beings and social interaction is an important part of societal membership [7], but the ability to do so, especially amongst an older population reliant on personal rather than digital communication, becomes hindered by illness or physical impediment. The concern is that the introduction of telecare may remove this social interaction element from a care package. Community telecare systems may contribute to social isolation significantly more than telemedicine [7] [27] and this is further exacerbated by conventional interaction being displaced by telephonic communication. Indeed the Social Care Institute for Excellence [7] has found that direct social contact with carers is of vital importance to older people, especially those living alone. Those from lower socio-economic groups visit their general practitioners more [28] [29] but use NHS Direct less [30], which suggests that these groups may trust direct contact with social carers more than remote surveillance. Furthermore, studies have shown that 'the socially isolated are over six times more likely to die from a stroke and more than three times as likely to commit suicide when compared to people with many social ties' [27] and the impact of social exclusion on psycho-social health is a well documented phenomenon [31]. For example, Palinkas et al. [32] found that depressive symptoms are inversely associated with size of social networks. There is however also some evidence to suggest that 'telecare can improve the amount and quality of social interaction' [7] by freeing up family and other carers; allowing more time for social engagement, although this assumes plentiful access to a social network.

The new national FACS (Fair Access to Care Services) framework for allocating social care resources, prioritises care and recognises the loss of social support systems and relationships, even in 'low' and 'moderate' levels[33]. However, with a marked reduction in councils offering social care at these levels, there is concern that maintaining social contact is not a funding priority [7], with many opting for telecare as a cheaper alternative to direct care. Combined with strained public finances, an increasing elderly population and the proliferation of cheaper and more capable telecare systems, it is possible that the resulting impact of social isolation could have a negative effect on the mental health of future generations of older people.

This throws open the wider question as to how such social isolation can be mitigated. Crucially, telecare should 
supplement and not replace direct social care unless patients have access to a sizeable social network. Furthermore as younger age groups are increasingly likely to lead more physically isolated lives due to reliance on digital communication technologies, it may be postulated that, in the future, telecare will have a minimal impact on social isolation; especially should telecare become integrated into smart homes and wearable technology.

\section{Conclusion}

The expanding use of telecare increases the importance of clarifying the 'standard of care' for informal or unpaid carers and the lack of technical standards will continue to hinder innovation and interoperability. Telecare is abundant with ethical issues and although guidelines can help resolve conflicts, the lack of binding service standards is a concern. Internet infrastructure must be improved to support next generation equipment and quality will become consistent as the industry grows. There is a case for an improvement in social care provision, in addition to telecare subsidies and finally, the social isolating effect of telecare may be reduced in the future as a technology-savvy generation ages.

\section{References}

1. TSA. Telecare Code of Practice: Setting Service Standards in Telecare. Telecare Services Association, 2010.

2. Stanberry, B.A. Legal and Ethical Aspects of Telemedicine. London : RSM Press, 1998.

3. Stanberry, B. Legal and Ethical Aspects of Telemedicine. [ed.] R. Wooten, J. Craig and V. Patterson. Introduction to Telemedicine. 2nd. London : RSM Press, 2006, pp. 151-167.

4. Darkings, A.W. and Cary, M.A. Telemedicine and Telehealth. London : Springer, 2000. pp. 128-152.

5. Herring, J. The Legal Duties of Carers. Medical Law Review. 2010, Vol. 18, 2.

6. Care for older people in the United Kingdom: problems, provision and policy. Grundy, E. Costa Rica : LSE, 2010. Seminario: Experiencias internationalces y propuestas.

7. Perry, et al. Ethical issues in the use of telecare. Social Care Institute for Excellence, 2010.

8. Department of Health. Telecare and Ethics. 2005.

9. Mill, J.S. On liberty. London : Longmans, 1875.

10. Daniels, N. Just Health Care. s.1. : CUP, 1985. p. Chap 1.

11. Norris, A.C. Essentials of Telemedicine and Telecare. s.1. : John Wiley and Sons, 2002. p. Chapter 1.3.

12. EU Communications Committee. Broadband access in the EU: situation at 1 July 2010. EU Information Society and Media Directorate-General, 2010.

13. Van Dijk. Broadband Internet Access Cost. EU Information Society and Media Directorate-General, 2010.

14. E-Health Insider. Telecare can grow to meet demands of 2020. [Online] 2501 2007. [Cited: 0712 2010].

http://www.e-health-insider.com/news/item.cfm?ID=2441.
15. Jones, P. Triennial Review: Education (Lifelong Learning) - Internet Access and Use. Equality and Human Rights Commission, 2010.

16. The motivations of domiciliary care providers in England: new concepts, new findings. Kendal, et al. 4, 2003, Journal of Social Policy, Vol. 32, pp. 489-511.

17. The attitudes of multiprofessional teams to telehealth adoption in northern Finland health centres. Vuononvirta, et al. 6, RSM, 2009, J Telemed Telecare, Vol. 15, pp. 290 - 296.

18. Commission care services for older people - the view from care managers, users and carers. Ware, et al. 4, 2003, Ageing and Society, Vol. 24, pp. 411-428.

19. Developing and validating the French-Canadian version of the practitioner and organizational telehealth readiness assessment tools. Légaré, et al. 3, RSM, 2010, J Telemed Telecare, Vol. 16, pp. 140-146.

20. Age UK. Paying for permanent residential care. 2010.

21. Wigan Council. Paying for Community Care Services. [Online] 2011. [Cited: 0601 2011].

http://www.wigan.gov.uk/Services/HealthSocialCare/FairAcc ess/CostofServices.htm.

22. Office for National Statistics. Pensioner Income and Expenditure. 2010. Note: A single woman is used in the calculations, being the lowest earners, to illustrate affordability.

23. Office for National Statistics. State Pensions. 2009.

24. Department of Health. Building Telecare in England. 2005.

25. Socioeconomic Inequalities in Health: Evidence on Patterns. Graham, H. 2, 2006, Benefits, Vol. 14, pp. 77-90.

26. Gheera, M. Funding social care. House of Commons Library Research, 2010.

27. Social Implications of Telehealth and Telecare Technologies. Dabrowska, E. and Cornford, T. AISeL, 1998. Americas Conference on Information Systems.

28. Socio-economic status and the utilisation of physicians' services: results from the Canadian National Population Health Survey. Dunlop, S., Coyte, P.C. and McIsaac, W. 1, 2000, Social Science \& Medicine, Vol. 51, pp. 123-133.

29. Socio-economic differences in the utilisation of health services in Belgium. Van der Heyden, J.H. et al. 2, 2003, Health Policy, Vol. 65, pp. 153-165.

30. Equity of access to health care. Evidence from NHS Direct in the UK. Knowles, et al. 5, 2006, J Telemed Telecare, Vol. 12, pp. 262-265.

31. Cox, B.D., Huppert, F.A. and Whichelow, J.M. The health and lifestyle survey: Seven years on. Aldershot : Dartmouth Publishing, 1993.

32. The biocultural context of social networks and depression among the elderly. Lawrence, et al. 4, 1990, Social Science \& Medicine, Vol. 30, pp. 441-447.

33. Brand, D., Green, L. and Statham, D. Facts about FACS: A guide to Fair Access to Care Services. Social Care Institute for Excellence, 2010. 